Revista lus et Praxis, Año 19, № 2, 2013, pp. 447 - 464

ISSN 0717 - 2877

Universidad de Talca - Facultad de Ciencias Jurídicas y Sociales

"Las cargas probatorias dinámicas:

¿Es indispensable darse toda esta vuelta?"

Diego Palomo Vélez

\title{
LAS CARGAS PROBATORIAS DINÁMICAS: ¿ES INDISPENSABLE DARSE TODA ESTA VUELTA?*
}

Diego Palomo Vélez

I. LOS MODELOS DE PROCESO Y SUS PRINCIPALES MARCAS:

A PROPÓSITO DE LAS VÍAS A SEGUIR POR LAS REFORMAS PROCESALES.

EL DEBER DE COLABORACIÓN, LA LEALTAD PROCESAL Y EL

SOLIDARISMO DE LAS PARTES EN LA ACTIVIDAD PROBATORIA

Las reformas procesales como las que vienen implementándose en el país ( $y$, por cierto, en otros países, desde mucho antes) responden en mayor o menor medida a materializaciones más o menos puras de concepciones que del proceso en general se han defendido, y que luego, especialmente desde la segunda mitad del siglo XIX, se han traducido en marcas (positivas y negativas) en la concreta configuración de los diversos principios, reglas e institutos que sirven en su estructuración.

En efecto, y simplificando al máximo la explicación circunscribiéndola sólo a lo necesario para la contextualización de lo que puede servir para entender el apogeo de la fórmula de las cargas probatorias dinámicas, en el abordaje de las visiones que en torno al proceso se sostienen se ha coincidido en destacar la existencia de dos grandes concepciones que han estado permanentemente luchando dogmática, ideológica y normativamente por la hegemonía. Una es la concepción liberal, la otra la concepción publicista ${ }^{1}$.

La primera, llevada hasta las últimas consecuencias, y desde la reivindicación del principio dispositivo y del respeto a las garantías procesales, especialmente

* Colaboración recibida el 24 de octubre y aprobada el 28 de octubre de 2013.

Este trabajo se realiza dentro del marco del proyecto Fondecyt Regular: "Estudio crítico del nuevo proceso laboral chileno a la luz de las exigencias del derecho al debido proceso" ( $\left.\mathrm{N}^{\circ} 1120409\right)$, y constituye una de las ponencias de las II Jornadas Nacionales de Derecho Procesal, realizadas los días 7 y 8 de noviembre de 2013 (Santiago, Chile). Acá se incluyen varias notas a pie de página que hemos estimado pueden resultar de interés para el lector que desee profundizar en el problema.

** Profesor de Derecho procesal en la Universidad de Talca, Doctor en Derecho por la Universidad Complutense de Madrid. Correo electrónico: dpalomo@utalca.cl

${ }^{1}$ Véase, entre otros, Montero Aroca, J., "Las concepciones garantista y autoritaria del proceso civil en el siglo XX". Revista del Instituto Panamericano de Derecho Procesal, pp. 223 y ss. En: http://egacal.educativa.com/upload/Q2009_MonteroJuan.pdf [visitado el 12/10/2013]. 
la imparcialidad del tribunal ${ }^{2}$, importó fundamentalmente la inadmisión de matizaciones en la afirmación de que las partes son dueñas del proceso, lo que desde luego implicó una concepción que terminó exagerando las limitaciones que debían consagrarse en la actuación de los jueces más allá de lo que resulta ser razonable con el desarrollo adecuado del proceso. Así, por ejemplo, y considerando que bastaba con las ansias de justicia de las partes como motor natural del proceso, se asume que el juez no debiera estar autorizado para hacer avanzar de oficio el procedimiento, estando privado no sólo de poderes materiales que ligan con el fondo de la controversia que deben resolver, sino que también se le priva de poderes procesales vinculados a la dirección e impulso del procedimiento que le permitirían adoptar de oficio todas las medidas que considere pertinentes para el válido, eficaz y pronto desarrollo del procedimiento, de modo de conducirlo sin dilaciones indebidas al estado de poder pronunciar la sentencia.

La segunda, postulando la necesidad de escapar de los problemas y deficiencias de la concepción liberal, incurrió en el mismo defecto de la exageración dogmática y normativa llegando a levantar modelos procesales con postulados ideológicos que coincidían en la consideración del proceso como un mal social, la desconfianza en las partes y el reforzamiento del protagonismo y poderes de dirección formal y material de los jueces que son llamados a encabezar, como representantes de un Estado que abandona su tradicional posición de pasividad, un modelo procesal que persiga establecer la verdad como condición para resultado justo, lo que a partir de Klein y su ZPO de 1895 viene siendo conocido como proceso social que, con el atractivo eslogan de garantizar la efectividad de la tutela jurisdiccional en la sociedad moderna, hizo fama y sumó adeptos gracias a la constante y amplia difusión realizada por parte de la doctrina procesal durante todo el siglo pasado e incluso el actual ${ }^{3}$. La evolución experimentada por los modelos procesales concretos en diversos países, europeos primero,

\footnotetext{
${ }^{2}$ Véase Monteleone, G., "L'imparzialitá del giudice e la prova nel proceso", Rivista I/ Giusto processo civile, vol. II, 2012, pp. 323 y ss.

${ }^{3}$ Se instala la expresión "neoprocesalismo" que serviría para identificar esta forma de concebir y entender la eficiencia de la jurisdicción y del proceso. Véase: GozAínı, O., "El neoprocesalismo", Revista Iberoamericana de Derecho procesal, Año VI, Núm. 9, 2006, pp. 227 y ss.; González Álvarez, R., Neoprocesalismo: teoría del proceso civil eficaz, Ed. Ara, Lima, 2013. También ha sumado críticos que han escrito sobre lo que consideran peligros de esta tendencia procesal. Véanse, por ejemplo, los siguientes trabajos: Correia de MendoncA, L., "Virus autoritario e processo civile", Rivista II Giusto processo civile, vol. I, 2008, pp. 115 y ss.; CAVAllone, B., "In difesa della veriphobia (considerazioni amichevolmente polemiche su un libro recente di Michelle Taruffo)", Rivista di Diritto processuale, Núm. I, 2010, pp. 1 y ss.; Calvinho, G., "La procedimentalización posmoderna", en Cárdenas Guzmán, M. y Sodi SerRet, C. (Coord. vol.), Derecho procesal civil y mercantil, México DF, Ed. Porrúa, centro de Investigación e Informática Jurídica, Obra jurídica enciclopédica, en Homenaje a la Escuela Libre de Derecho en su primer centenario, 2012, pp. 135 y ss.
} 
latinoamericanos después, evidencia una progresiva instalación de un modelo de enjuiciamiento que apuesta por un cambio de paradigma que va de la mano de la presencia y participación activa del juez $z^{4}$ a lo que se suma con destacado énfasis el predominio del principio de cooperación eficiente de las partes con el juez y del juez con las partes, interacción y dinámica colaborativa que identificaría la estructuración de un modelo procesal sustancialmente dirigido a producir una sentencia justa ${ }^{5}$.

Destacándose esta perspectiva, se ha señalado que una de las contribuciones más importantes de Klein en el tema de la adquisición del material de prueba y la fijación de los hechos siempre en la búsqueda de la justa decisión de la controversia, está referida especialmente al desarrollo del deber de cooperación de las partes del proceso y su obligación de información recíproca, lo que incide en la dimensión ética del comportamiento de las partes y del proceso mismo ${ }^{6}$. En este esquema la colaboración, la buena fe y lealtad procesal, la moralización del proceso ${ }^{7}$ y el Ilamado solidarismo toman la palabra buscando dejar atrás la idea del proceso como una contienda entre partes parciales enfrentadas ante un tercero imparcial, y en el afán de la búsqueda de la verdad objetiva impone la redefinición del principio de buena fe procesal para dar lugar a un deber de colaboración entre todos los que intervienen en el proceso, incluyendo deberes asistenciales del juez, y los deberes de veracidad e integridad de las partes ${ }^{8}$.

\footnotetext{
${ }^{4}$ Peyrano, J., "El cambio de paradigmas en materia procesal civil", en Peyrano, J. (Dir.), Principios procesales, Ed. Rubinzal-Culzoni, Buenos aires, Tomo I, 2012, pp. 131 y ss.

${ }^{5}$ HazArd, G.; Dond, A. Etiche della professione legale, Ed. Il Mulino, Bolonia, 2005, p. 98.

${ }^{6}$ Así se destaca especialmente en Trocker, N., "La concezione del processo di Franz Klein e l'attuale evoluzione del diritto processuale civile europeo", Rivista I/ Giusto processo civile, vol. I, 2012, pp. 55 y ss.

${ }^{7}$ Cappellettı, M., "Le grandi tendenze evolutive del proceso civile nel diritto comparato", en Cappellettı, M., Processo e ideologie, Ed. Il Mulino, Bolonia, 1969, pp. 169.
}

${ }^{8}$ Destacan: "1) El deber del juez de asesorar a las partes sobre los derechos y obligaciones que le corresponden, lo que supone también la necesidad de estimular la actividad procesal de las partes y realmente de todos los demás que intervienen en el proceso, Ilegándose a hablar de una suerte de funciones asistenciales encomendadas al juez que deben operar incluso cuando las partes comparecen asistidas por abogado. 2) Correlativamente el deber de las partes, no ya de aportar los hechos al proceso informando al juez, sino de hacerlo sin esconder hecho alguno y haciéndolo siempre de manera veraz, de modo que han de llevar al proceso todo aquello de lo que tienen conocimiento. Se trata de un deber de veracidad e integridad o, de otra manera, de lealtad y probidad". Muy crítico de esta redefinición, Montero Aroca, J. "Sobre el mito autoritario de la buena fe procesal", en Montero Aroca, J., Proceso civil e ideología, Ed. Metropolitana, Santiago, pp. 315 y 316 . También puede leerse críticamente a CIPRIANI, F., "El centenario del Reglamento de Klein (el proceso civil entre libertad y autoridad)", en CiprianI, F., Batallas por la Justicia Civil, Ed. Cultural Cuzco, Lima, 2003, pp. 59 y ss. En sentido favorable al reconocimiento y justificación de un deber de colaboración en materia procesal civil, véase, entre otros a: Mitidiero, D., Colaboración en el proceso civil: presupuestos sociales, lógicos y éticos, Ed. Communitas, Lima, 2009. 
Esta tendencia publicista ha sido exitosa y productiva en los textos, pero no ha logrado traducirse en un salto cualitativo en la superación de la crisis de la Justicia en la realidad de los sistemas procesales que han aplicado disciplinadamente su fórmula. Basta con constatar la situación en la actualidad de muchos países, especialmente de nuestra Región, que siguen padeciendo una crisis de la calidad y eficiencia de la Justicia a pesar de la influencia clara y predominante de la concepción publicista del proceso ${ }^{9}$. Tampoco se trata de reivindicar la fórmula de la pasividad judicial absoluta, neoliberal, inmovilista, o retrógrada, como se han preocupado de difundir torcidamente varios autores interesados en llevar sus particulares concepciones hasta las últimas consecuencias, vinculándolas, por cierto, al progresismo y modernidad procesales que tendrían, en esta línea, una única vía de desarrollo posible. Es que somos de la opinión que desde hace tiempo que las diferencias de planteamiento que puedan existir en torno a las concepciones de modelos procesales más o menos abiertos a un rol protagonista de los jueces no pueden simplificarse en un modo que muchas veces pierde de vista la realidad de las concretas regulaciones procesales que recogen un reforzamiento de este rol, ignora interesadamente (ya que así sale más sencillo descartar las posiciones contrarias) que en la actualidad ya nadie controvierte seriamente la necesidad de dotar a los jueces de mayores poderes que resultan perfectamente atendibles como cuando se trata de los poderes de dirección formal o procesal, y peor aún, olvida que el propósito de las reformas procesales debe estar siempre centrado en la mejora efectiva de la Administración

\footnotetext{
${ }^{9}$ Ya nos hemos pronunciado en otros lugares, a propósito del caso chileno, en torno al cada vez más evidente e insostenible problema de los procesos de reforma en general, pero especialmente en las reformas a los sistemas procesales no penales, imponiéndose, en los hechos y en la realidad, una nueva Justicia que atiende a una mirada unidimensional de la eficiencia que se hace recaer casi exclusivamente en la celeridad de la respuesta jurisdiccional y en las estadísticas judiciales, como si la rapidez fuese el supremo bien del proceso, postergando de manera preocupante la dimensión cualitativa que queda mermada en sus posibilidades en una esquema de funcionamiento que poco contribuye a cuidar que la calidad de la justicia diga relación sobre todo con la calidad de la información que sirve de sustento a la decisión jurisdiccional. Muestra de esta mirada unidimensional de la eficiencia en nuestro país (y también en otros países de la Región que han seguido similar ruta en el plano de las reformas procesales) lo constituye la tolerancia a la utilización extorsiva del mecanismo de la conciliación como una forma de presionar indebidamente a las partes para llegar a un acuerdo, ya sea para ahorrarse el trabajo de continuar con el juicio o por la consecución de ciertas metas institucionales. También constituye una clara muestra del problema denunciado la superficialidad y precipitación que caracterizan muchas veces el desarrollos de nuestros procedimientos que han apostado por la fórmula de la oralidad en donde el manejo de una agenda de audiencias que contempla escaso tiempo para ellas (muchas veces sin atender a sus particularidades) termina afectando no sólo la calidad de las decisiones, sino que se traducen en limitaciones intolerables al debido proceso. Sobre estos problemas, véase también: Ríos Leiva, E., "La oralidad en los procesos civiles en América Latina. Reflexiones a partir de una observación práctica", en Aportes para un diálogo sobre el acceso a la Justicia y reforma procesal civil en América Latina, Centro de Estudios de Justicia de las Américas, Santiago, 2013, pp. 95 y ss.
} 
de Justicia a partir del diseño de sistemas procesales que no sólo sean nuevos, sino viables y mejores abundando los planteamientos reformistas realizados en abstracto y desde arriba (desde el olimpo personal como ilustrativamente dice De la Oliva).

Por todo lo señalado, y sin perjuicio de destacar la superioridad de los modelos predominantemente adversariales que permiten una mejor Justicia ${ }^{10}$, bien regulados desde luego, y con las dosis necesarias y razonables de actuación judicial, pero dónde sean las partes y sus abogados quienes deban asumir la responsabilidad central de ingresar y controlar la información que servirá de sustento a la sentencia, es que nos parece a esta altura más razonable dejar de lado estos enfrentamientos ideológicos y hasta políticos que, en buena medida, han desatendido la prudencia de partir por considerar aspectos tan básicos como importantes, vinculados sobre todo al factor humano que tiene a su cargo el funcionamiento del sistema, lo que debe siempre incluir a los jueces y también a los abogados, la conveniencia de poner de relieve la relevancia de una mayor responsabilidad en los intervinientes y la necesidad de una mayor modestia epistemológica a la hora de definir la distribución de roles entre las partes y el juez ${ }^{11}$.

\footnotetext{
${ }^{10}$ Recomiendo la lectura de un interesante estudio que, despejando el tema ideológico y político que muchas veces ha contaminado el análisis, así lo pone de relieve en: Ramos Romeu, F., "Proceso inquisitorial y proceso adversarial. Orígenes y funcionamiento en 109 países", Revista Justicia, Núm. 3-4, 2008, pp. 345 y ss. Refiriéndose a los reforzados y mayores poderes del juez en los sistemas predominantemente inquisitivos, Ramos Romeu pone en sus conclusiones una cuestión evidente: “...también está claro que dichos poderes no resuelven el problema, ni hacen que la justicia sea más prístina y pura. Al fin y al cabo la solución de atribuir mayor poder y responsabilidad al Estado sólo puede funcionar en la medida en que las personas que deban gestionar ese poder sean mejores o puedan hacerlo mejor, lo que es muy dudoso que los procesos de selección consigan. Los funcionarios y los jueces también son falibles, también tienen sus intereses y sus motivos espurios. Y sin contar con que, a su vez, el juez se convierte en fuente de incertidumbre y aleatoriedad en sus decisiones, cuando ocupa la primera página. El proceso adversarial, en cambio, tiene mejores resultados y posiblemente sea éste el motivo por el cual predomina en la escena mundial" (pp. 375 y 376$)$.

${ }^{11}$ En cuanto a los abogados, y en época de reformas, es útil que el legislador desarrolle su importante labor con seriedad, evitando populismos, y como bien se ha apuntado, devolviendo a las personas la convicción de que las leyes se dictan para ser cumplidas y no para ser reformadas. Añadidamente, y en lo que liga con la situación de la reforma y los abogados, el legislador deberá plantear una regulación que se levante sobre la constatación de estar en "un país de abogados", "un país con alto número de abogados a los que, p. ej., se acude a la hora de contratar, al menos cuando se trata de un contrato de importancia o atípico", y ante una "Justicia civil de abogados", "es decir, en un país en que, más o menos frecuentemente, o bien habitualmente, los procesos civiles complejos o simples, sobre asuntos de extraordinaria importancia o sobre cuestiones litigiosas cotidianas, se inician y desarrollan con intervención de abogados": De LA Oliva SANTOS, A., El papel del juez en el proceso civil. Frente a ideología, prudentia iuris, Ed. Civitas, Madrid, 2012, pp. 74 y ss.
} 


\section{LA REGLA DE LA CARGA DE LA PRUEBA:}

LOS PUNTOS DE VISTA DESDE EL CUAL SE PUEDE REVISAR, LA OBJETIVIDAD DE LA REGLA DEL ART. 1698.1 DEL CC, LAS FÓRMULAS LEGALES COMPLEMENTARIAS Y LA INNECESARIEDAD PROPUESTA DE LA TEORÍA DE LAS CARGAS PROBATORIAS DINÁMICAS

Realizada nuestra explicación preliminar en torno a las concepciones que se mantienen sobre el proceso, sintética, pero que permite sentar las bases de nuestra tesis en la materia que nos convoca, cabe destacar la relación que por algunos se ha pretendido exista entre la concepción de proceso y la necesidad de una nueva configuración de la regla de la carga de la prueba.

Pues bien, antes de llegar a dar cuenta de esta pretendida relación, conviene revisitar, aunque sea brevemente, algunos aspectos ligados a la regla de la carga de la prueba en general y en nuestro ordenamiento jurídico, para terminar definiendo la necesidad o no de introducir modificaciones a la misma en la línea que se viene postulando por la doctrina y también en el Proyecto de nuevo Código procesal civil (en adelante PNCPC).

La primera cuestión que debemos poner al servicio de la explicación de nuestra postura sobre esta materia es recordar la doble dimensión que cabe reconocer en la regla de la carga de la prueba. Por un lado, desde el punto de vista del juez, debemos hablar de una regla de juicio. Del otro, desde el punto de vista de las partes, hablamos de una regla de conducta para ellas, perspectiva que es la que en mayor medida se tiene presente cuando se piensa en la carga de la prueba. Otros prefieren referirse a carga de la prueba en sentido material y a carga de la prueba en sentido formal.

La regla de juicio que recoge la regla de la carga de la prueba en sentido material pone a disposición del juez una fórmula que le permite respetar el principio non liquet, el deber de inexcusabilidad ${ }^{12}$ y resolver la controversia sometida a su enjuiciamiento aun en los casos de insuficiencia probatoria, mostrándole cuál de las dos partes del proceso debe sufrir las consecuencias de la falta o insuficiencia probatoria. En consecuencia, la fórmula de la regla de la carga de la prueba como regla de juicio opera al momento de tener que dictar la sentencia y su presupuesto viene dado justamente por la existencia de hechos relevantes respecto de los cuales no se logró realizar una actividad probatoria exitosa. Montero lo explica con claridad y señala al respecto que el juez puede encontrarse en una de las siguientes situaciones ${ }^{13}: 1$ ) el hecho afirmado por la parte existió, en el sentido que sobre él la actividad probatoria

\footnotetext{
${ }^{12}$ Corral Talciani, H., "Sobre la carga de la prueba en el Proyecto de Código procesal civil", en AgulRREZABAL, M. (Coord.), Justicia civil: perspectivas para una reforma en la legislación chilena, Universidad de los Andes, Cuadernos de Extensión Jurídica 23, Santiago, p. 107.

${ }^{13}$ Montero Aroca, J., La prueba en el proceso civil, Ed. Civitas, Madrid, 2002, p. 87.
} 
ha producido certeza. En tal caso, en la sentencia el juez declarará probada la existencia del hecho y aplicará la consecuencia jurídica pedida por la parte; 2) el hecho afirmado por la parte no existió. En la sentencia, el juez deberá declarar la inexistencia del hecho y no se dará la consecuencia jurídica pedida por la parte; 3) el hecho afirmado no ha llegado a ser probado, sigue dudoso, por falta o insuficiencia de prueba. Es en este último caso cuando el juez, por aplicación del principio y deber antes señalados y por razones de seguridad jurídica, debe igualmente fallar, sin poder excusarse en la incerteza fáctica, para lo cual debe acudir a las reglas de la carga de la prueba.

La regla de la carga de la prueba como norma de conducta para las partes nos recuerda que el proceso en general y su eje central, la prueba, se estructura sobre la base de la noción de carga como imperativo del propio interés ${ }^{14}$. En otras palabras, centrándonos en la carga de la prueba, lo que se quiere destacar es que las partes no tienen el deber o la obligación de probar (en el sentido que su no ejercicio pueda provocar sanción o responsabilidad), pero si no son exitosos al levantar la "carga" de la prueba, la consecuencia negativa vendrá dada por una sentencia desfavorable a sus intereses. Bien se ha dicho que para las partes la carga de la prueba se traduce en una decisiva norma orientadora de su actividad y estrategia probatoria en el proceso, al punto que la parte que no levanta la carga que le corresponde resultará derrotado, pues el juez debe establecer las consecuencias de la falta de prueba de los hechos que una parte ha alegado, decidiendo en su contra: "El principio fundamental que se sigue en numerosos ordenamientos se expresa tradicionalmente a través del brocardo onus probandi incumbit ei qui dicit. Se trata de la versión procesal de una regla generalísima de fairness, en virtud de la cual, quien hace una afirmación debe estar listo y dispuesto, si es requerido, a demostrar la verdad de lo que ha afirmado"15.

\footnotetext{
${ }^{14}$ El concepto de carga es mérito de James Goldschmidt, que se refirió al dinamismo de la situación procesal en virtud del cual cada uno de los litigantes se halla sujeto a estados de expectativa, de riesgo y chances según su comportamiento activo y diligente que lo aproxima o aleja en cada instante de una sentencia favorable. Goldschmidt, J., Derecho procesal civil, Traducción de la 2da edición alemana por Leonardo Prieto Castro, Ed. Labor, Barcelona, 1936, pp. 201 y ss.

${ }^{15}$ TAruffo, M., Simplemente la verdad, el juez y la reconstrucción de los hechos, Ed. Marcial Pons, Madrid, 2010, pp. 255 y 256. Este autor, conocido por sus trabajos en donde ha próvido con bastante aceptación una visión publicista del proceso de la mano de un rol reforzadamente protagónico de los jueces civiles en la reconstrucción de la pequeña historia del proceso como condición necesaria para la resolución justa de las contiendas, toma distancia de lo que desde su sector se continúa postulando ahora en relación a la evolución de la regla de la carga de la prueba (y sobre lo cual enseguida nos hacemos cargo), expresando, por ejemplo, que le parece inaceptable que de una afirmación -no demostrada- de un hecho se puedan hacer derivar consecuencias jurídicas negativas de otro sujeto: "esto es lo que ocurriría si se admitiera que la demanda del actor pudiera ser acogida sin que éste probara la verdad de los hechos que ha alegado y, por tanto, se admitiera que el demandado pudiera perder el caso sin que el actor haya probado tener razón en los hechos. Atribuir, en el proceso, la victoria a
} 
En nuestro ordenamiento la carga de la prueba se encuentra regulada en el Código Civil (1698.1 CC) en los siguientes términos: "Incumbe probar las obligaciones o su extinción al que alega aquéllas o ésta". Al respecto no sobra consignar un par de apuntes. El primero, que si bien hace referencia a la prueba de las obligaciones nadie discute en la doctrina civil ni procesal, ni tampoco en la jurisprudencia que se trata de una norma aplicable a la prueba de los hechos ${ }^{16}$. El segundo, que si bien no lo señala expresamente y la norma pareciera contemplar sólo los hechos constitutivos y los extintivos, la interpretación doctrinal y jurisprudencial de la regla ha coincidido en considerar cubiertos también los hechos impeditivos y excluyentes, y que a partir de allí se ha precisado que la carga de probar los hechos normalmente constitutivos de su pretensión corresponde al actor y es carga del demandado la prueba de los hechos extintivos, impeditivos o excluyentes de la relación jurídica en discusión.

Esta norma ha servido hasta la fecha de criterio válido, razonable y general entre nosotros para distribuir la carga de la prueba en forma objetiva, donde en principio no influye la diversa dificultad de probar que exista para una parte respecto de la otra, o que pueda ser obra de las circunstancias personales en que cada una de ellas se pueda encontrar ${ }^{17}$, otorgando a éstas una regla clara, previamente conocida, contribuyendo a la seguridad jurídica ${ }^{18}$. Al buen resultado de esta regla general ha contribuido la intervención del legislador alterando la regla general de la carga probatoria en ciertos casos especiales, facilitando la prueba a alguna de las partes generando las excepciones necesarias para hacer frente a una serie de situaciones en las cuales puede tener especial dificultad o imposibilidad para levantar la carga según la regla general ${ }^{19}$. En efecto, para este fin el propio legislador ha recurrido a fórmulas complementarias de la regla

quien ha alegado un hecho sin demostrarlo parece un privilegio carente de justificación". Y lo hace sin apartarse de la función epistémica que le reconoce a la prueba: así señala que la carga de la prueba "apunta ante todo a imponer a quien haya alegado un hecho la carga de demostrar con pruebas que ese hecho ocurrió verdaderamente. Esta regla está dirigida, entonces, a favorecer la determinación de la verdad y a lograr que la decisión final se funde en esa determinación. Presiona a la parte que ha alegado un hecho para que suministre su prueba, amenazándola -por decirlo así- con la derrota en el caso que el hecho no resulte probado".

${ }^{16}$ Carvajal, P., "Non liquet! Facilidad probatoria en el Proyecto de un nuevo Código procesal civil", Revista Chilena de Derecho, vol. 39, Núm. 3, p. 568.

${ }_{17}$ Peñallııo, D., La prueba en materia sustantiva civil. Parte general, Ed. Jurídica de Chile, Santiago, 1989, p. 46.

${ }^{18}$ Carvajal, P., "Non liquet!", cit. nota n. 16, p. 566.

${ }^{19}$ Lo propio ha ocurrido en otros países, como España, actuando el legislador con medidas especiales para facilitar la prueba a alguna de las partes como contrapeso a diferentes realidades y en atención a criterios de política legislativa o para allanar las dificultades inherentes al caso, como acontece en la lucha contra la discriminación de género. Así se explica en Armenta Deu, T., "El derecho a la igualdad entre mujer y hombre: tutela procesal civil", Revista Jurídica de Cataluña, Núm. 1, 2010, pp. 53 y ss. 
general de la carga probatoria, ya sea por la vía de establecer directamente reglas que invierten, desplazan o aligeran el peso de la prueba ${ }^{20}$, o bien a través del mecanismo de las presunciones legales ${ }^{21}$ en donde "una norma le impone al juez tener por verdadero un hecho alegado por una parte, sin que exista ninguna prueba sobre él (en particular por iniciativa de la parte que lo ha alegado) y la verdad de este hecho continúa siendo vinculante para el juez si es que la otra parte no prueba lo contrario" 22 .

El Proyecto anuncia en esta materia lo que califica como un "nuevo y más justo" tratamiento a la tradicional carga de la prueba, introduciendo la posibilidad (excepcional, precisa el Mensaje) que el juez distribuya la carga conforme a la disponibilidad y facilidad probatoria que posea cada una de las partes en el litigio. Así, frente a la rigidez e inflexibilidad que se dice caracterizaría a la regla general del art. 1698.1 CC, se propone abrir paso a la modificación judicial de la carga de la prueba "a fin de poder corregir eventuales desigualdades entre

${ }^{20}$ Un ejemplo del legislador chileno es el caso de la regulación contemplada a propósito de los procesos de tutela laboral (art. 493 Código del Trabajo), dónde el trabajador denunciante deberá acreditar sólo indiciariamente la existencia de la vulneración de derechos fundamentales, correspondiendo al denunciado explicar los fundamentos de las medidas adoptadas y su proporcionalidad, cuestión calificada como un importante avance "en la carrera con obstáculos que es la protección efectiva de esos derechos": UGarte CATALDO, J., "La tutela de los derechos fundamentales y el Derecho del trabajo: de erizo a zorro", Revista de Derecho, Universidad Austral de Chile, vol. XX, Núm. 2, 2007, p. 65. Taruffo admite que estas definiciones especiales del legislador pueden ser objeto de críticas, ya que puede haber disenso respecto de la preferencia que éste ha asignado a ciertos sujetos y no a otros. Pero advierte que en estos casos de definición legal especial el proceso y el juez se mantienen en el trasfondo debiendo sólo ejecutar ciertas elecciones de política legislativa que han sido adoptadas antes y fuera del proceso: TARUfFo, M., Simplemente la verdad, cit. nota n. 15, p. 261.

21 "Así, por ejemplo, el deudor debe probar su diligencia (art. 1547 del Código Civil), se presume la responsabilidad del tercero civilmente responsable por el ilícito del dependiente (arts. 2320 y 2322 del Código Civil), se presume la paternidad si el demandado se niega injustificadamente a someterse a una prueba biológica (art. 199 inc. 4 del Código Civil)...". Corral, H., "Sobre la carga de la prueba", cit. nota n. 12, p. 109. Aunque en ocasiones, como se ha destacado por Peñailillo, la fórmula complementaria de las presunciones no constituya realmente una alteración del peso de la prueba, como ocurre con la presunción recogida en el art. 700 del Código Civil, que presume dueño al poseedor de la cosa: PeÑallılo, D., La prueba en materia sustantiva civil, cit. nota n. 17, p. 64. "Si se examina la realidad, puede comprobarse que lo normal es que quienes detentan cosas con ánimo de dueño, lo son; y excepcionalmente no lo son; entonces, si no existiera la presunción del art. 700, en un caso concreto el juez, al distribuir el peso de la prueba cuando una de las partes está poseyendo la cosa, la impondría del mismo modo, es decir, tendría por dueño al poseedor y diría que si el otro afirma que el poseedor no es dueño, estaría alegando algo contrario a lo normal y, por tanto, él debería probar que el contrario no es dueño (esa presunción no implica, pues, una alteración de la regla general del onus probandi)".

${ }^{22}$ Taruffo, M., Simplemente la verdad, cit. nota n. 15, p. 260. Se ha dicho que tratándose de las presunciones no hay inversión de la carga de la prueba, sino que añaden una carga de la contraprueba, que normalmente no existe. "En ellas hay un juicio de probabilidad que enlaza los dos (o más) supuestos de hecho y que fundamenta la norma positiva de presunción, pero no impide la prueba en contrario": Armenta Deu, T., "El derecho a la igualdad", cit. nota n. 19, p. 53. 
las partes", en lo que se conoce como la institución de la carga dinámica de la prueba, la que (sigue el Mensaje) "ha tenido amplia aceptación y aplicación en el Derecho comparado como un instrumento que otorga al juez, con los debidos resguardos legales, la posibilidad excepcional de distribuir la carga de la prueba conforme a la disponibilidad y facilidad probatoria de las partes, asegurando de este modo la vigencia de los principios de justicia, cooperación y buena fe procesal" $^{\prime 23}$. En Latinoamérica uno de los procesalistas que más ha escrito sobre este tema, al punto que no pocos lo entienden el creador de la fórmula de las cargas dinámicas de la prueba, es el argentino Jorge W. Peyrano ${ }^{24}$, que ha visto en los criterios de disponibilidad y facilidad que recogen algunas nuevas regulaciones procesales (por ej., LEC la española y ahora, agregamos nosotros, el PNCPC chileno) una mera denominación de recambio de lo que en el país trasandino se conoce como la doctrina de las cargas probatorias dinámicas o visión solidarista de la prueba, concebida a su juicio como un mecanismo de mejor reparto de los esfuerzos probatorios y como una flexibilización de las interpretaciones rígidas del mecanismo de distribución del onus probandi y que determina que frente a circunstancias excepcionales, por aplicación de las reglas de la sana crítica, la carga probatoria venga a recaer en la parte con mayor disponibilidad o facilidad probatoria ${ }^{25}$.

Es precisamente esta modificación judicial de la carga probatoria que se pretende autorizar en el PNCPC la que concentra las críticas que la propia fórmula de las cargas dinámicas ha venido acumulando en la doctrina, sin

\footnotetext{
${ }^{23}$ Se propone un artículo 294 que de prosperar el Proyecto en este punto sustituiría al art. 1698.1 CC. La norma que genera discusión se recoge en el inciso segundo: "El tribunal podrá distribuir la carga de la prueba conforme a la disponibilidad y facilidad probatoria que posea cada una de las partes en el litigio lo que comunicará a ellas, con la debida antelación, para que asuman las consecuencias que les pueda generar la ausencia o insuficiencia de material probatorio que hayan debido aportar o no rendir la prueba correspondiente de que dispongan en su poder". Este inciso está pendiente de aprobación en la Comisión de la Cámara de Diputados, justamente por tratarse de una de las propuestas más controvertidas del PNCPC, como ya lo advirtió parte de la doctrina procesal, gran parte de la doctrina civil y la propia Corte Suprema cuando le correspondió informar el Proyecto, oportunidad en la cual señaló expresamente no compartir el rol asignado al juez en esta materia, y que las reglas de la carga de la prueba deben estar definidas con anterioridad al inicio del proceso, no resultado apropiado que pueda determinar la carga según el caso y antecedentes que se le presenten por el riesgo de generar situaciones arbitrarias.

${ }^{24}$ Véase: Peyrano, J. (Dir.), Cargas probatorias dinámicas, Ed. Rubinzal- Culzoni, Santa Fé, 2004. Aunque el mérito mayor de Peyrano en esta materia dice relación con la denominación de la fórmula y su difusión en nuestra Región, debido a que ya muchos años antes el inglés Jeremias Bentham escribía en su Tratado de las pruebas judiciales sobre la parte que debía probar en un juicio en un sentido y enfoque similar: aquélla que pueda practicarla con menos inconveniente, es decir, con menos dilaciones y gastos, será la parte que deba probar. Sobre este punto véase: CALVINHO, G., "Cargas probatorias dinámicas: exotismo y magia que desnaturalizan la garantía del proceso civil", Revista Brasileira de Dereito Processual, Año 21, Núm. 82, 2013.

${ }^{25}$ Peyrano, J., Problemas y soluciones procesales, Ed. Juris, Rosario, 2008, pp. 349 y 350.
} 
perjuicio de la sentida apelación a la confianza en los jueces que un admirado y querido procesalista ha planteado entre nosotros, justificando en este sentido el reconocimiento de un criterio subjetivo del juzgador, de la mano de la orientación publicista que, sabemos, marca su concepción del proceso ${ }^{26}$. Hace años se escribía sobre esta fórmula de las cargas probatorias dinámicas que comenzaba a hacer fama en Argentina: "tiende a justificar, para los casos excepcionales en que corresponde aplicarla, que se libere total o parcialmente al litigante constreñido a probar según las normas clásicas y aun modernas sobre el onus probandi, para trasladar y desplazar sobre el demandado dicho esfuerzo verificatorio cuando se halla en mejor disponibilidad de los medios de prueba. Se le imputa a éste, al menos, el deber de colaboración en busca de una eficiente administración de justicia" 27 .

Se propone, entonces, asumir una fórmula que asociada al neoprocesalismo, en esta versión, está profundamente marcada por la subjetividad de los criterios que le sirven de orientación y la discrecionalidad judicial en que se permite su concreción que, en algunos países (como acontece en la propia Argentina, también en Uruguay), termina materializando un modelo de juez decisionista y un modelo de proceso que no sólo afecta negativamente la seguridad jurídica, sino también el derecho de defensa y el principio del contradictorio a partir de la permisividad con la sorpresa de la definición judicial de última hora ${ }^{28}$. Este judicialismo del caso concreto de generación sin sustento legal ha sido objeto de críticas también por autores reconocidamente partidarios de un reforzado protagonismo de los jueces, destacando los problemas que genera frente a la debida imparcialidad judicial y reconociendo la significativa dificultad de autorizar a los jueces un poder discrecional para manipular la carga probatoria de un modo diverso al contemplado por la ley ${ }^{29}$,

\footnotetext{
${ }^{26}$ Tavolari Oliveros, R., “¿Confianza o desconfianza en los jueces?: un alegato a favor de conferir mayores oportunidades a la justicia, a propósito de la polémica por las cargas probatorias dinámicas o principio de facilidad de la prueba", Revista de Derecho Procesal: Proyecto de Código procesal civil, Universidad de Chile, Núm. 22, 2012, pp. 355 y ss.

${ }^{27}$ EISNER, I., "Desplazamiento de la carga probatoria", La Ley, 1994, C, p. 846.

${ }^{28}$ Corral Talciani, H., "Sobre la carga de la prueba", cit. nota n. 12, p. 112. También: Alvarado Velloso, A., La prueba judicial. Reflexiones críticas sobre la confirmación procesal, Ed. Librotecnia, Santiago, 2009, p. 69; VAlentín, G., "Análisis crítico de la Ilamada teoría de las cargas probatorias dinámicas", Revista Uruguaya de Derecho procesal, Núm. 3-4, 2008, pp. 356 y ss.

29 "Estas manipulaciones de las cargas probatorias por obra de los jueces pueden depender de diversas razones. En algunos casos se fundan en valoraciones sensu lato equitativas (o, en la peor hipótesis, judicialistas), en virtud de las cuales el juez considera justo y equitativo reequilibrar la posición de las partes a fin de hacer posible, o de facilitar, la tutela del derecho de un sujeto procesalmente débil. Otras veces se considera oportuno atribuir la carga de la prueba a la parte que dispone del medio de prueba o que está más cerca de él. Otras veces se considera que no vale la pena pedir a una parte que prueba algo que a primera vista parece normal, y que, en cambio, es oportuno requerir
} 
peor aún cuando dicha manipulación judicial sólo se produce al momento de dictar la sentencia ${ }^{30}$, cuando la parte a la cual se le hace soportar la carga redistribuida ya no puede probar.

La propuesta local plantea un matiz al imponer al juez el dar aviso, en la audiencia preliminar ${ }^{31}$, de esta distribución de la carga de la prueba que atienda a los criterios antes señalados, donde lo dispuesto por el art. 294.2 operaría, según lo han destacado sus promotores, como una fórmula de corrección del criterio general de distribución de la carga de la prueba que, según se desprendería de la propia redacción de la norma en cuestión (el tribunal podrá distribuir...), estaría llamado a funcionar complementariamente y sólo en casos de excepción, para atemperar el rigor que pudiera llegar a ocasionar la aplicación estricta e inflexible de las normas generales de la carga de la prueba. Este aviso anticipado ya significaría, se destaca, un avance significativo en la -a esta altura- desmejorada situación que existe para principios fundamentales del proceso en aquellos sistemas judiciales que operan bajo la fórmula más desbordada de la teoría de las cargas probatorias dinámicas, como ocurre en el caso argentino ya aludido.

Pero cabe preguntarse si esta medida inmuniza la propuesta de problemas y riesgos de afectación de derechos y principios básicos como el derecho de defensa y el principio del contradictorio. La simple verificación de la oportunidad procesal del aviso que se contempla, esto es, la audiencia preliminar, debiera hacer saltar las alarmas si no se quiere terminar configurando un modelo que en esta materia afecte postulados elementales de justicia. En efecto, tanto desde el Derecho procesal como desde el Derecho civil se ha observado críticamente la fórmula criolla de recepción de la teoría de las cargas probatorias dinámicas, destacándose que la cuestión de la oportunidad sigue siendo un problema mal resuelto. Así, Pinochet ha señalado que la mitigación de los problemas de la concreción chilena de la teoría de las cargas probatorias dinámicas es sólo aparente, ya que si nos tomamos verdaderamente en serio la vigencia del puñado de derechos procesales fundamentales toda persona debe saber con antelación al juicio cuáles son sus cargas en materia probatoria, no sirviendo

\footnotetext{
a la parte que ha alegado un hecho anormal o excepcional que proporcione su demostración. Con todo, justificaciones como éstas parecen bastante débiles". TARUfFo, M., Simplemente la verdad, cit. nota n. 15, p. 263.

${ }^{30}$ TARuffo, M., Simplemente la verdad, cit. nota n. 15, p. 265.

${ }^{31}$ Así se lee del art. 294.2, que debe relacionarse con el art. 280 núm. 9: "El tribunal deberá realizar la comunicación a que se refiere el artículo 294. En caso que el tribunal haga uso de la facultad que le confiere el inciso segundo de dicha norma, la parte podrá, para el sólo efecto de satisfacer la carga probatoria impuesta por el tribunal, ejercer el derecho contemplado en el artículo 276". Este último artículo hace referencia a las alegaciones complementarias, la alegación de hechos nuevos o desconocidos, y la ampliación de prueba.
} 
de nada que esto ocurra en la audiencia preparatoria ${ }^{32}$. O como ha puesto de relieve Corral, "es absurdo que las partes sean comunicadas que el juez ha variado la carga de la prueba en la audiencia preliminar y tengan como plazo esa misma audiencia para tratar de satisfacer la carga que sorpresivamente el juez les ha atribuido" ${ }^{\prime 33}$. Si el propósito de la comunicación judicial en esta oportunidad procesal era permitir a la parte actuar en consecuencia a fin de ejercer plenamente su derecho defensa, pareciera que la regulación propuesta no asegura esta efectividad y puede generar hipótesis de indefensión que debieran ser repudiadas en un modelo procesal que pretende levantarse desde el respeto a los principios jurídico naturales del proceso.

Además, la propuesta en referencia no constituye, a nuestro juicio, la respuesta legislativa más adecuada para hacer frente a problemas que pueden enfrentarse a través de definiciones legales, ya sea por la vía de establecer directamente el legislador unas reglas que "inviertan" ${ }^{34}$, desplacen o aligeren el peso de la prueba (perfeccionando y ampliando las reglas ya existentes), o bien a través del mecanismo de las presunciones legales, fórmulas que no constituyen un atentado a la seguridad jurídica y advierten con antelación a la entrada al juicio y por mecanismos objetivos cuál será la distribución de las cargas probatorias en determinados casos en que resulte justificado, por considerarlo así el legislador, apartarse de la regla general que rige en la materia.

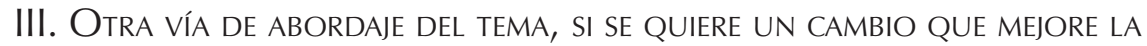 SITUACIÓN ACTUAL SIN INTRODUCIR ELEMENTOS QUE COMPROMETAN EL DERECHO DE DEFENSA Y LA SEGURIDAD JURÍDICA: MEJOR REGULACIÓN DE LAS CONSECUENCIAS \\ DESFAVORABLES DE LA CONDUCTA DE LAS PARTES EN LA ACTIVIDAD PROBATORIA}

Con todo, dicho lo anterior, y ya cerrando las consideraciones generales y particulares que hemos estimado oportuno traer a colación respecto de la fórmula reformista recogida sobre la carga probatoria de las partes, no podemos dejar de observar que tenemos la impresión que muchas veces el problema que se quiere abordar cuando se invoca entre nosotros la teoría de la carga probatoria dinámica, poco tiene que ver en realidad con la cuestión involucrada

\footnotetext{
32 Pinochet Cantwell, F., "Cargas dinámicas de la prueba. El agravamiento en Chile", en Gómez Colomer, J.; Barona Vilar, S.; y Calderón Cuadrado, P. (Coords.), El Derecho procesal español del siglo XX a golpe de tango, Ed. Tirant lo Blanch, Valencia, 2012, p. 742.

${ }^{33}$ Corral Talcianı, H., "Sobre la carga de la prueba", cit. nota n. 12, pp. 115 y 116.

${ }^{34}$ Aunque en rigor, como bien señala Muñoz Sabaté, no cabe hablar de inversión cuando es el legislador el que establece una norma especial atributiva del onus probandi. En este caso, técnicamente, no se está ante una inversión de la carga probatoria, sino frente a una "simple y pura modificación de la norma" general. Muñoz Sabaté, L., Fundamentos de prueba judicial civil. LEC 1/2000, Ed. Bosch, Barcelona, 2001, p. 181.
} 
a propósito de la carga dinámica (con todo el soporte de nuevos principios o principios redefinidos que ellos imponen de la mano con la nueva concepción de proceso que se abraza), y mucho, en cambio, con la necesidad de perfeccionar la colaboración en la práctica de los medios de prueba, en general, y con la disponibilidad de los medios de prueba, en particular. La propia redacción de la norma propuesta en la materia así pareciera ponerlo en evidencia, situándose en un punto intermedio que no contribuye en aportar claridad en la definición del problema que se quiere abordar y el instrumento que se quiere utilizar: "El tribunal podrá distribuir la carga de la prueba conforme a la disponibilidad y facilidad probatoria que posea cada una de las partes en el litigio lo que comunicará a ellas, con la debida antelación, para que asuman las consecuencias que les pueda generar la ausencia o insuficiencia de material probatorio que hayan debido aportar o no rendir la prueba correspondiente de que dispongan en su poder" ${ }^{\prime \prime 35}$.

Al respecto, de inmediato debemos consignar, por obvio que resulte, que no es realista aspirar a que las partes (sus abogados) incorporen al proceso pruebas que les perjudiquen y favorezcan a la contraria: no sólo es impropio de la naturaleza humana ${ }^{36}$, sino que iría contra del deber profesional del abogado con su cliente. El abogado debe luchar y defender la posición jurídica de su cliente haciendo uso de todas las herramientas legales. Como bien ha destacado Montero, nadie ha postulado ni postula que todo vale, pero tampoco es razonable pretender que se colabore espontáneamente para que venza la contraria, menos pretendiendo una cuestión que es extraña a la realidad práctica de los juicios, cual es que creer que antes del inicio de un proceso la verdad "resplandece y deslumbra a todo el que la mira". Siempre nos ha resultado extraño que se sostenga por algunos la existencia de un supuesto deber de todas las partes, directas o indirectas, y sus abogados, que deriva de lo que se viene denominando como la moralización del proceso, de prestar leal y diligente colaboración para el efectivo descubrimiento de la verdad (recuérdese lo apuntado al inicio sobre los deberes de veracidad e integridad) y la buen funcionamiento del Servicio público de la Justicia, donde aquéllas sacrifiquen su interés particular por fines superiores. Y acá nos referimos no sólo a los procesos que cuentan con una regulación decimonónica, como nuestro

\footnotetext{
${ }^{35}$ La norma que recoge la LEC española (art. 217.6) es del siguiente tenor: "Para la aplicación de lo dispuesto en los apartados anteriores de este artículo el tribunal deberá tener presente la disponibilidad y facilidad probatoria que corresponde a cada una de las partes del litigio".

36 "La nueva ley procesal civil no debía desconocer la naturaleza humana" decía De la Oliva refiriéndose a la nueva LEC española. Véase: De la Oliva Santos, A., "Verificación de los criterios esenciales de la Ley 1/2000, de Enjuiciamiento Civil, en sus primeros meses de vigencia", en Gómez Colomer, JL. (Coord.), La aplicación práctica de la ley de enjuiciamiento Civil de 2000, Ed. Tirant lo Blanch, Valencia, 2003, p. 27.
} 
proceso civil, sino también a la realidad de los procesos en general, también los reformados en el último tiempo.

Por cierto, entendemos que podrá constituir una afirmación que no sea compartida por aquéllos autores que sostienen la concepción de un proceso social que tiene atribuido fundamentalmente un fin público de la mano de las bases consignadas por Klein y su ZPO, pero no podemos suscribir (arriesgando nadar a contracorriente, otra vez) la idea muy de moda y difundida que sostiene que los problemas de la Justicia se superan desde una concepción procesal que se traduce en medidas que terminan o pueden terminar afectando la distribución más razonable de los roles y responsabilidades que cabe reconocer a las partes y sus abogados, por un lado, y a los jueces, por el otro.

Dejando a un lado estas teorías que parecieran ver a una abogacía situada en la "Ínsula Utopía" ${ }^{37}$, reivindicamos la importancia que cabe reconocer en el rol que corresponde asumir a los abogados en un proceso entendido como instrumento de garantía ${ }^{38}$, esto es, un instrumento que se levanta respetuoso de los postulados elementales de justicia sin los cuales se hace irreconoscible o deriva en mero procedimiento. En este modelo procesal "los abogados deben asumir la defensa de los derechos e intereses legítimos del cliente con todas las fuerzas de la propia inteligencia y capacidad, utilizando todos los medios que la ley regula y permite" ${ }^{\prime \prime 39}$. Y uno de los objetivos más caros que debiera perseguir todo proceso de reforma debiera ser el relegitimar la relevancia de la función que corresponde cumplir a los abogados ${ }^{40}$, evitando que este afán de reforzar el protagonismo de los jueces termine normalizándose el apoderamiento del proceso por parte de ellos, dejando a los abogados en un segundo plano especialmente problemático para la buena salud del sistema, con todas las consecuencias negativas que ello acarrea desde la perspectiva del contradictorio

\footnotetext{
${ }^{37}$ De la Oliva Santos, A., Casación, oralidad y nuevo proceso civil. Tres conferencias chilenas, Ediciones Jurídicas de Santiago, Santiago, 2009, p. 74. Un tipo de ideal de parte-utópico-que poco o nada tiene que ver con la realidad y que ilustrativamente se ha descrito de la siguiente manera: "Este tipo ideal de parte presupone una persona que, con la mayor imparcialidad, pueda presentar su versión de los hechos al tribunal, pidiendo sólo lo que la ley le permite y ayudando, sea al tribunal, sea a la parte contraria, en la recolección de todo aquello que contribuya a arribar al resultado final más justo: una parte que no aspira a persuadir, sino a informar al tribunal, que no actúa estratégicamente en función del mejor resultado que sirva a sus intereses, sino que coopera sistemáticamente con el tribunal y con la parte contraria". Correia de Mendonca, L., "Virus autoritario e processo civile", cit. nota n. 3, p. 137.

${ }^{38}$ Correia de Mendonca, L., "Virus autoritario e processo civile", cit. nota n. 3, p. 121.

${ }^{39}$ Correia de Mendonca, L., "Virus autoritario e processo civile", cit. nota n. 3, p. 121.

${ }^{40}$ En esta misma línea escribíamos hace algún tiempo: PAlomo Vélez, D., "Deberes de aviso e información del juez y de esclarecimiento y colaboración de las partes y una cuestión que ha vuelto a ponerse de moda: los poderes del juez civil. Comentario de una conferencia", en Palomo Vélez, D., Reforma procesal civil: Oralidad y poderes del juez, 2010, Santiago, p. 373.
} 
y el derecho de defensa, como también desde la perspectiva de la calidad de la información que va a servir de base a la sentencia que definirá la contienda ${ }^{41}$.

A partir de aquí, y de acuerdo a lo advertido al iniciar este último apartado, el desafío principal de la reforma en este punto no está tanto en la consagración legal de la posibilidad de manipulación de las cargas probatorias por parte de los jueces, sin o con un aviso como el previsto en la propuesta (que no lo inmuniza de problemas, según vimos), sino que viene dado por el perfeccionamiento que puede darse a la regulación procesal en lo que dice relación con las hipótesis en que se busca que una parte pueda recurrir a pruebas que estén disponibles para la otra parte. En estos casos es innecesario e incorrecto recurrir a la alteración de la regla general de la carga de la prueba, sino que será suficiente (y más correcto, señala Taruffo) "prever una orden de exhibición, efectiva y adecuadamente sancionada que impusiera a la parte que dispone de la prueba que sería útil a la otra parte aportarla al juicio"42. En otras palabras, como resulta previsible que la parte no incorpore al proceso las pruebas que le perjudican, debiera el legislador hacerse cargo de regular de mejor manera la consecuencia procesal perjudicial para los intereses de la parte que no aporte una prueba ${ }^{43}$ que, en todo caso y teniendo a la vista la configuración de la propuesta probatoria en el Proyecto (inicial y concentrada) ${ }^{44}$, debe contemplar la exigencia para la parte que no dispone del medio de prueba de solicitar en esa oportunidad procesal inicial la exhibición probatoria en cuestión.

La clave debiera estar en lograr una fórmula moderna pero equilibrada, que esquive al máximo el subjetivismo y la imprevisibilidad de las decisiones judiciales y que, por un lado, permita minimizar el riesgo que una parte no tenga éxito por dificultades de acceso a la prueba (Cristián Riego y Felipe Marín en este sentido $)^{45} y$, por el otro, tome los resguardos necesarios para evitar su mala utilización, lo que debiera imponer su regulación como instrumento

\footnotetext{
41 "No se puede creer en una justicia social predefinida antes del debate procesal, ya que sólo la peculiaridad del caso concreto logran obtener, mediante el contradictorio entre las partes y el que juzga, la formación de la decisión adecuada. La verdadera democracia procesal se obtiene, entonces, sólo distribuyendo la responsabilidad social y política de todos los sujetos del proceso". NUNES, D., "Il ruolo della magistratura nel processo moderno", Rivista I/ Giusto proceso Civile, vol. 1, 2007, p. 114.

${ }^{42}$ TARUfFo, M., Simplemente la verdad, cit. nota n. 15, p. 263.

${ }^{43}$ Una denuncia a las variadas dificultades y problemas de la heterogénea e insuficiente regulación procesal vigente en esta materia, en: PinOchet Cantwell, F., "Cargas dinámicas de la prueba", cit. nota n. 32, p. 737.

${ }^{44}$ Bordalí Salamanca, A.; Cortez Matcovich, G.; Palomo Vélez, D., Proceso civil. El juicio ordinario de mayor cuantía, Ed. Abeledo Perrot, Santiago, 2013, p. 233. Véase también: Palomo Vélez, D., "Las marcas del proceso oral y escrito diseñado en el proyecto de nuevo CPC chileno", en PALOmo Vélez, D., cit. nota n. 44 , p. 113.

${ }^{45}$ Véase: http://www.reformasprocesales.udp. cl/materiales-de-discusion-rpc/opinion-y-prensa/cargade-la-prueba/ [visitado el 12/10/2013].
} 
excepcional a partir de una solicitud expresa y debidamente fundada en cuanto a la verosimilitud de la existencia de la prueba en cuestión a disposición de la contraria $^{46}$ (por lo que nunca debiera bastar el sólo hecho de que una de las partes afirme en su respectivo escrito de alegación inicial que su contraria tiene en su poder una prueba de la cual desea servirse). Si la parte incumpliera o dificultara injustificadamente la resolución judicial que acepta el requerimiento de exhibición y producción probatoria planteado por la contraria en la oportunidad procesal ya consignada, debiera desplegarse una consecuencia procesal perjudicial a través de la cual se valore dicha conducta probatoria, debiendo el juez interpretarla, en un modelo de sana crítica como es el que recogen las últimas reformas y también ésta, como una confirmación de la fijación, para los efectos del proceso y su sentencia, de las afirmaciones de la parte contraria respecto del hecho que se pretendió probar, a menos que las otras pruebas que se hayan practicado ya sea a petición de parte o bien de oficio lleven al juez a descartar la señalada consecuencia, en coherencia con el reforzamiento que la reforma procesal pretende dar al deber de motivación de las sentencias. En definitiva, lo que habrá en estos casos, siguiendo a Muñoz Sabaté ${ }^{47}$, será una rebaja de la dosis de prueba a cargo del actor y considerarla saturada con la presunción endoprocesal desprendida por la conducta del demandado. "Es la conducta del demandado lo que historifica la afirmación del actor. El actor adquiere para su acervo probático la conducta del demandado. La carga de la prueba no se convierte, sino que se considera saturada. Si algo se desplaza sobre el demandado no es ciertamente la carga primaria de la prueba, sino, como lo hemos dicho, la carga de contraprobar la presunción endoprocesal que él mismo ha desprendido con su conducta".

\footnotetext{
${ }^{46}$ VAlentín, G., "Análisis crítico", cit. nota n. 28, pp. 356 y ss. A disposición de la contraria, o bien por su mayor facilidad de acceso a la prueba. Al respecto Muñoz Sabaté intenta precisar estas nociones que, a su juicio, coincidimos, importan una conducta procesal de las partes por lo que trascienden a la propia regla de distribución del onus probandi y se incardinan también en el área de valoración de la prueba (aunque haciendo referencia a los que denomina principios correctores de la regla general incorporados en el art. 217 de la LEC: "Ambos principios no son operativos si no se da una posición de contraste. La disponibilidad o la facilidad probatoria de una parte carece de significado si la contraparte se halla en idéntica posición de disponibilidad o facilidad. El principio de disponibilidad hace referencia a una situación de cercanía, acceso o contacto del litigante con el medio o la fuente de prueba, lo cual le permite su traslado al proceso sin obstáculos de mayor género... La indisponibilidad negligente, entendiendo como tal la falta de previsión en la preconstitución o conservación de una prueba sobre un hecho que pudiera resultar favorable a la contra parte, puede devenir a veces equivalente en sus efectos, a una plena disponibilidad. El principio de facilidad tiene un carácter más genérico, pues obviamente comprende al de disponibilidad. Tal vez podamos brindar algún ejemplo específico suponiendo el caso de que la prueba resulte más económica, más rápida, más fiable o más segura de poderse practicar, o en caso de ciertos hechos negativos. Lo cierto es que los tribunales emplean a veces el término facilidad, aunque sin demasiadas pretensiones diferenciadoras". MuÑOZ SABATÉ, L., Fundamentos de prueba, cit. nota n. 34, pp. 178 y 179.

${ }^{47}$ Muñoz Sabaté, L., Fundamentos de prueba, cit. nota n. 34, p. 183.
} 
Terminemos a través del clásico ejemplo que ha servido, hasta ahora, para difundir la teoría de las cargas probatorias dinámicas, de mala praxis médica, donde, por ejemplo, los peritos nombrados se niegan a informar y la demandada no aporta la ficha clínica. Comentando una sentencia, Muñoz Sabaté precisa: "Por un lado la sentencia recurrida considera negativa sospechosa de los peritos médicos que habían sido propuestos por las partes, actitud que impidió practicar en trámite ordinario la prueba pericial médica, tan necesaria en estos casos. $\mathrm{Ni}$ que decir tiene que la razón de esa sospecha parece bastarse en una habitual confabulación entre la clase médica, de lo que obviamente no es ajeno el demandado. De ahí que se le acuse de obstaculizar la prueba o no cooperar de buena fe en su práctica. Por otro lado se valora igualmente el hecho de la inexistencia de una historia clínica de la paciente, cosa que no solo hace mucho más dificultosa la prueba, sino que evidencia una falta de, cuando menos, rigurosidad profesional por parte del propio médico y del mismo centro hospitalario demandados. También aquí la carga primaria de la prueba pretende satisfacerla la actora, víctima del acto médico. Precisamente por ello debió proponer la prueba pericial médica y el requerimiento al demandado para que aportase su historial clínico" ${ }^{\prime 4}$. En consecuencia, la fórmula que suscribimos por parecer más razonable no justifica ni ampara la pasividad de la parte demandante que, en casos como éste, sencillamente se conforme con "cruzarse de brazos" 49 aspirando a la aplicación judicial de la teoría de las cargas probatorias dinámicas. Somos del parecer que en dichos casos no corresponde consagrar autorizaciones para que los jueces manipulen las cargas probatorias, pasando por encima no sólo la noción misma de carga procesal, sino que el derecho de defensa y el principio del contradictorio. Las partes (sus abogados) deben tener siempre una actitud activamente probatoria, y en esa línea debiera ir la nueva regulación.

\footnotetext{
${ }^{48}$ Muñoz Sabaté, L., Fundamentos de prueba, cit. nota n. 34, p. 185.

${ }^{49}$ Muñoz Sabaté, L., Fundamentos de prueba, cit. nota n. 34, p. 185.
} 